\title{
Efeito da Cloração da Água de Beber e do Nível Energético da Ração sobre o Ganho de Peso e Consumo de Água em Frangos de Corte
}

\author{
Renato Luis Furlan ${ }^{1}$, Marcos Macari², Euclides Braga Malheiros ${ }^{3}$, Caetano Ingraci ${ }^{4}$, Helena \\ Torres Meireles ${ }^{4}$
}

\begin{abstract}
RESUMO - Dois experimentos foram realizados com o objetivo de pesquisar o efeito da adição de cloro à água de beber e dos diferentes níveis de energia na ração sobre o ganho de peso e consumo de água em frangos de corte. No experimento 1, as aves foram alimentadas com dois níveis de energia metabolizável na ração (2900 e $3200 \mathrm{kcal}$ EM/kg) em cada fase da criação. Foi observado que o nível energético não influi no consumo de água e no ganho de peso dos frangos de corte. No experimento 2, o nível de energia metabolizável da ração foi de $3200 \mathrm{kcal} \mathrm{EM} / \mathrm{kg}$ e a água de beber foi clorada com hipoclorito de sódio a $11 \%$, correspondendo a 5 ppm de cloro. O consumo de água foi menor nas aves que receberam água clorada. Apesar de o consumo de água ter sido menor, não houve redução no ganho de peso das aves que receberam hipoclorito de sódio. A adição de cloro à água de beber melhorou os índices bacteriológicos. Os resultados obtidos nestes experimentos evidenciam que os níveis energéticos das rações testadas não influenciaram o consumo de água dos frangos de corte; entretanto, a adição de cloro reduziu a ingestão de água, porém sem influir no ganho de peso nas aves tratadas.
\end{abstract}

Palavras-chave: frangos de corte, hipoclorito de sódio, energia, ingestão de água, sexo

\section{Effect of Drinking Water Chlorination and Dietary Energy Level on Body Weight Gain and Water Intake in Broiler Chickens}

ABSTRACT - Two experiments were conducted to study the effect of adding chlorine on drinking water and different dietary energy levels on the body weight gain and water intake in broiler chickens. In Experiment 1, broilers were fed diets containing two levels of energy (2900 and $3200 \mathrm{kcal} \mathrm{ME} / \mathrm{kg}$ ) in each growing phase. The dietary energy level did not affect the water intake and the body weight gain of the broilers. In experiment 2, the dietary metabolizable energy level was $3200 \mathrm{kcal} \mathrm{ME} / \mathrm{kg}$ and drinking water was treated with sodium hypochlorine at $11 \%$ corresponding to $5 \mathrm{ppm}$ of chloride. The water intake was reduced in the birds that received chlorated drinking water, however, there was no reduction on body weight gain in birds that received sodium hypochlorine. The addition of chlorine to the drinking water improved the bacteriological index. The results obtained in this experiment evidence that the tested dietary energy level did not affect the broiler water intake; however, the addition of chlorine reduced the drinking water intake without influence on body weight gain of the treated birds.

Key Words: broiler, sodium hypochlorine, energy, drinking water, sex

\section{Introdução}

A água é o mais importante nutriente para qualquer espécie animal, tendo participação em processos fisiológicos como digestão, transporte e absorção (MACARI et al., 1994); desempenha papel fundamental no processo de perda de calor durante o estresse calórico (TEETER, 1994), além de servir como via de ingestão de vacinas e medicamentos (SIMON e OLIVEIRA, 1996). Em seu estado natural, é um dos compostos de maior pureza que se conhece, porém, atualmente, dificilmente encontrase fonte de água doce que não tenha suas características alteradas pelo homem (MACARI, 1996).
A qualidade da água é caracterizada por gosto, odor, salinidade, $\mathrm{pH}$, demanda química de oxigênio, presença de nitritos, fosfatos e contaminantes de origem microbiana e/ou industrial (VOHRA, 1980). Neste sentido, AMARAL et al. (1995), estudando mananciais de abastecimento situados na zona rural brasileira, verificaram que $90 \%$ das amostras de água de poços e $10 \%$ das água oriundas de minas apresentaram bactérias indicadoras de poluição fecal. AMARAL et al. (1994), também, observaram a presença de microorganismos indicadores de poluição fecal, em fontes de abastecimento de água superficiais e subterrâneas, representadas por córregos, drenos e poços artesianos. Esses dados

\footnotetext{
${ }^{1}$ Professor Assistente Doutor, Departamento de Morfologia e Fisiologia Animal, FCAV/UNESP, Rodovia Paulo Donato Castillane, Km 5 - 14.870 000 - Jaboticabal, SP. (016) 323-2500; FAX 322-4275; E-mail: rlfurlan@fcav.unesp.br

2 Professor Titular, Departamento de Morfologia e Fisiologia Animal, FCAV/UNESP.

${ }^{3}$ Professor Titular, Departamento de Ciências Exatas, FCAV/UNESP.

${ }^{4}$ Estudante do Curso de Zootecnia da FCAV/UNESP.
} 
são muito importantes para a avicultura, pois a contaminação das fontes de água torna-se problema em potencial, que prejudica o desempenho de frangos e galinhas (GRIZZLE et al., 1997a).

O cloro, devido a sua eficiência, custo, praticidade e inocuidade, quando utilizado de maneira correta, tem sido o produto mais comumente empregado para desinfeção da água de dessedentação, tanto para humanos como para animais. MURPHY et al. (1987) constataram que a cloração contínua da água de beber de frangos de corte a 2 ppm reduziu significativamente o número de bactérias. Os mesmos autores verificaram também redução no consumo de água, embora a taxa de crescimento não tenha sido influenciada. Em outra pesquisa, DAMRON e FLUNKER (1993) observaram redução da ingestão de água por frangos de corte, quando estes receberam água contendo $100 \mathrm{ppm}$ de cloro, e redução no peso corporal, quando receberam água contendo 300 ppm de cloro. MOORE et al. (1971) já haviam observado peso corporal menor em frangos que receberam água clorada.

Um dos mais importantes fatores que influi na ingestão de água pelas aves é a ingestão de alimento, por ser capaz de alterar todo o equilíbrio, interferindo na água metabólica, isto é, água proveniente do metabolismo intermediário (MACARI, 1995). BARTHOLOMEW e CADE (1963) mostraram que a oxidação de proteínas, carboidratos e gorduras forneceram, respectivamente, 0,$6 ; 0,5$; e $1,2 \mathrm{~g}$ de água por grama de produto metabolizado. A associação direta do nível protéico e a quantidade de água consumida estão provavelmente relacionadas ao fato de que maior quantidade de água é necessária para o metabolismo da proteína que carboidrato ou gordura (PATRICK, 1955).

Nesse sentido, dois experimentos foram conduzidos com o objetivo de estudar os efeitos da cloração da água de beber e do nível de energia da dieta sobre o ganho de peso e a quantidade de água ingerida em frangos de corte.

\section{Material e Métodos}

Foram utilizados 1600 pintos da linhagem HubbardPeterson, sendo metade de cada sexo, criados de 1 a 49 dias. As aves foram alojadas em galpão convencional de alvenaria, com divisões internas (boxes) de 1,5 m de largura $\times 3 \mathrm{~m}$ de comprimento. Cada divisão estava equipada com bebedouros pendulares automáticos e comedouros tubulares com capacidade

para 20 quilogramas.

Durante o período experimental, todas as aves consumiram ração ad libitum. No Experimento 1, foram utilizadas rações à base de milho e farelo de soja, sendo uma inicial do $1^{\circ}$ ao $28^{\circ}$ dia de idade e uma de crescimento do $29^{\circ}$ ao $49^{\circ}$ dia de idade, formuladas com dois níveis de energia metabolizável, 2900 e $3200 \mathrm{kcal}$ $\mathrm{EM} / \mathrm{kg}$ de ração, em cada fase da criação (Tabela 1).

No Experimento 2 foi utilizada ração à base de milho e farelo de soja, sendo uma inicial do $1^{\circ}$ ao $28^{\circ}$ dia de idade e uma de crescimento do $29^{\circ}$ ao $49^{\circ}$ dia de idade, formuladas com apenas um nível energético, $3200 \mathrm{kcal} \mathrm{EM} / \mathrm{kg}$ de ração, para as duas fases de criação. As rações experimentais foram calculadas utilizando-se as tabelas de composição de ingredientes e exigências nutricionais de ROSTAGNO et al. (1985) (Tabela 1).

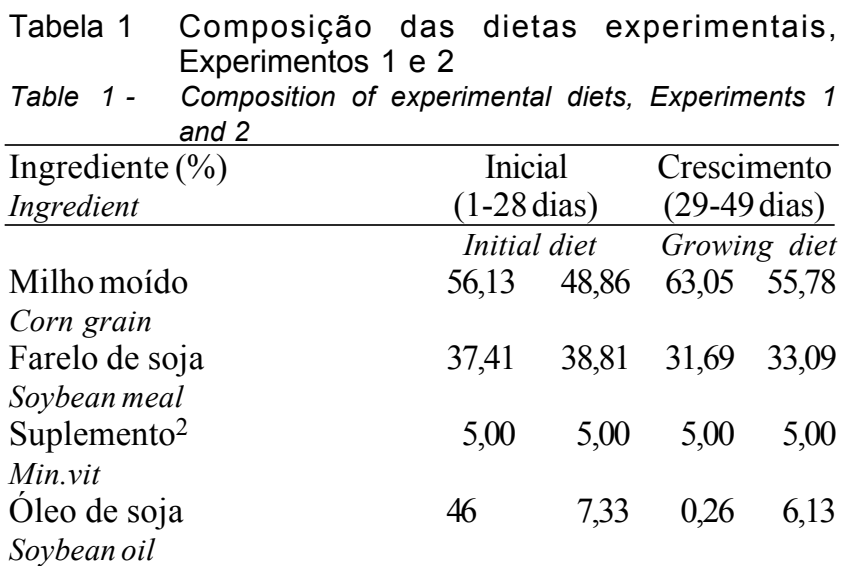

Soybean oil

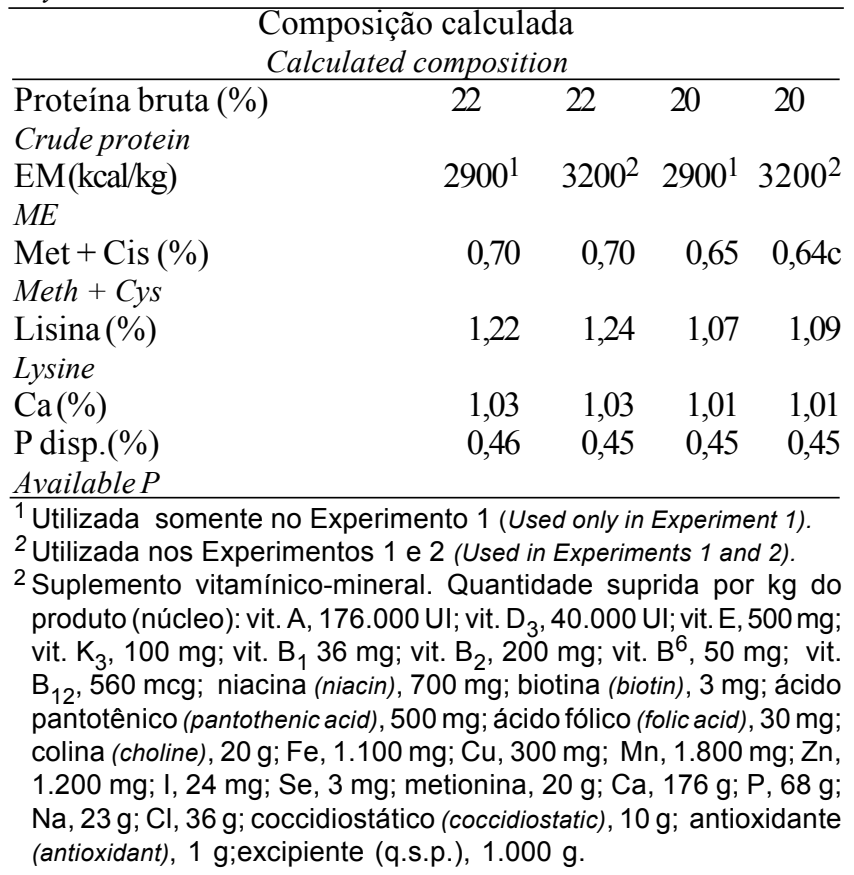




\section{Experimento 1}

A proposta deste experimento foi estudar diferentes níveis de energia da ração e do sexo sobre o consumo de água e ganho de peso dos frangos de corte. Oitocentos frangos de um dia de idade, metade de cada sexo, foram aleatoriamente distribuídos em quatro tratamentos, sendo as aves pesadas no $1^{\circ}, 28^{\circ}$ e $49^{\circ}$ dia de idade, para obtenção do ganho de peso. A quantificação do consumo de água foi obtida adaptando-se um galão de 5 litros em cada bebedouro pendular, sendo realizadas medições a cada 12 horas.

O delineamento experimental utilizado foi o inteiramente casualizado segundo esquema fatorial 2 x 2 com os fatores: energia metabolizável (2900 e $3200 \mathrm{kcal} \mathrm{EM} / \mathrm{kg}$ ) e sexo (macho e fêmea), com cinco repetições por tratamento, sendo cada parcela constituída por 40 aves. As análises de variância foram realizadas por meio do pacote computacional ESTAT (Sistema de Análises Estatísticas, 1996).

\section{Experimento 2}

A proposta deste experimento foi estudar o efeito da cloração da água de beber sobre o consumo de água e ganho de peso de frangos de corte. Foram utilizados oitocentos pintos de 1 dia de idade, metade de cada sexo, criados de 1 a 49 dias de idade. No $1^{\circ}$, $28^{\circ}$ e $49^{\circ}$ dia de idade, foram efetuadas pesagens das aves de cada tratamento experimental para obtenção do ganho de peso.

A quantificação do consumo de água foi obtida de acordo com procedimento adotado no Experimento 1. $\mathrm{Na}$ cloração da água, foram colocados $0,83 \mathrm{~mL}$ de hipoclorito de sódio a $11 \%$ em 5 litros de água, o que correspondeu a $5 \mathrm{ppm}$. O cloro residual livre (ppm) foi determinado por intermédio do Método OtaColorimetria com disco, no $1^{\circ}, 2^{\circ}, 3^{\circ}, 9^{\circ}, 16^{\circ}, 41^{\circ}$ e $47^{\circ}$ dia de idade, coletando-se $5 \mathrm{~mL}$ de água dos bebedouros a cada 2 horas. A qualidade da água foi verificada com base nos seguintes parâmetros: demanda química de oxigênio (DQO), sólidos totais (ST), amônia, $\mathrm{pH}$ e bacteriológico, por meio da capacidade formadora de colônias em agar, sendo amostrada água de 2 bebedouros de cada tratamento, tomando-se o cuidado de não repetir, nas amostragens do dia, os bebedouros dos quais a água já havia sido amostrada. As amostras de água foram coletadas de $3 \mathrm{em} 3$ horas, das 8 às $17 \mathrm{~h}$, aos 15,30 e 45 dias de idade.

O delineamento experimental utilizado foi o inteiramente casualizado, segundo esquema fatorial $2 \times 2$ com os fatores: água (com e sem adição de cloro) e sexo (macho e fêmea), com cinco repetições por tratamento, sendo cada parcela constituída por 40 aves. As análises de variância foram realizadas por intermédio do pacote computacional ESTAT (Sistema de Análises Estatísticas, 1996).

\section{Resultados e Discussão}

De acordo com os resultados apresentados no Experimento 1 (Tabela 2), os níveis de energia da ração não tiveram efeito significativo sobre o ganho de peso final dos frangos de corte, embora tenha sido obtida diferença $(\mathrm{P}<0,05)$ entre os tratamentos na fase inicial de criação (1 a 28 dias de idade). Os resultados também mostraram que não houve influência significativa do nível energético da ração sobre o consumo de água (Tabela 2).

Analisando o efeito de sexo (Tabelas 2 e 3), observou-se que os machos apresentaram valores superiores $(\mathrm{P}<0,01)$ de ganho de peso em relação às fêmeas nos dois experimentos. Pela análise das Tabelas 2 e 3 , constata-se que houve efeito significativo $(\mathrm{P}<0,01)$ de sexo sobre o consumo de água, em que os machos apresentaram médias de ingestão de água superiores às fêmeas.

No Experimento 2 (Tabela 3), a ingestão de água foi influenciada pela cloração da mesma. A análise estatística de todo o período experimental revelou que o consumo de água foi significativamente menor nas aves que receberam água clorada, no entanto, do $1^{\circ}$ ao $28^{\circ}$ dias de idade não houve diferença na ingestão de água. Entretanto, a adição de hipoclorito de sódio à água de beber não influenciou o ganho de peso das aves (Tabela 3).

O efeito da cloração sobre a qualidade da água está sumarizado na Tabela 4. Os resultados mostraram que a adição de cloro à água de beber manteve o pH estável e reduziu a demanda química de oxigênio, a porcentagem de sólidos totais e o número de bactérias (expresso em unidades formadoras de colônias - UFC). Houve redução da concentração do cloro na água de beber (Tabela 5), em função do tempo e idade das aves.

O desempenho das aves está relacionado com a qualidade dos nutrientes recebidos. GRIZZLE et al. (1997a) mostraram que frangos de corte expostos a fontes de água contaminada com nitrato e $E$. coli exibiram reduzido peso vivo a $4^{\mathrm{a}}$ e $6^{\mathrm{a}}$ semanas de vida. Reprodutoras pesadas que também receberam água contaminada reduziram significativamente a produção e a fertilidade dos ovos (GRIZZLE et al., 1997b). Neste trabalho, verificou-se que o ganho 
FURLAN et al.

Tabela 2 - Efeito do nível energético da ração e sexo sobre o ganho de peso (g) e consumo de água Experimento 1

Table 2 - Effect of dietaryenergy and sex on weight gain and water intake Experiment 1

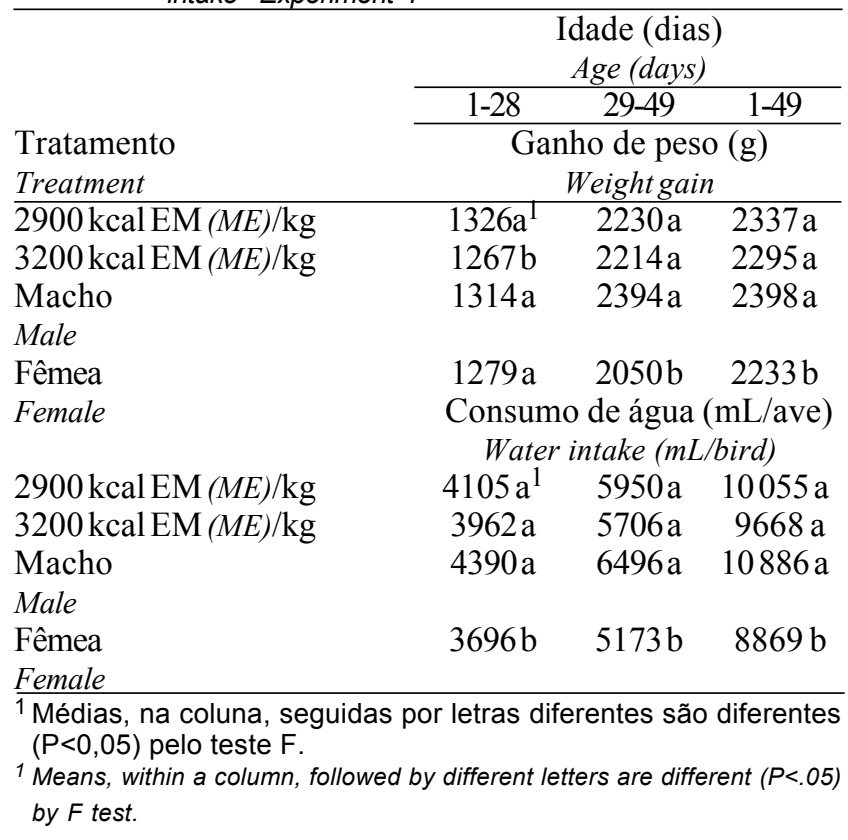

de peso dos animais que receberam água clorada (Tabela 3) foi $58 \mathrm{~g}$ maior por ave, o que representou $2,57 \%$ a mais de peso quando comparado as aves que não receberam água clorada. Os resultados sugerem que o aumento no ganho de peso foi resposta à ingestão de água de melhor qualidade, com conseqüente redução na competição por nutrientes no trato gastrintestinal. Os níveis de energia da ração (Tabela 2- Experimento 1) não tiverem efeito significativo sobre o ganho de peso final dos frangos de corte. LEESON et al. (1992) observaram que o crescimento e o peso final foram ligeiramente reduzidos em frangos de corte que receberam dieta diluída. Estes resultados podem estar relacionados com a capacidade dos frangos de corte em ajustar a ingestão de alimento e, conseqüentemente, o ganho de peso, com base no nível energético da ração (HOWIE, 1996).

PATRICK e FERRISE (1962) mostraram aumento no consumo de água em frangos que receberam altos níveis de proteína na ração. Outros trabalhos têm relatado que o consumo de água também pode ser elevado por determinadas substâncias, como o bicarbonato de sódio e o cloreto de potássio. BRANTON et al. (1986) mostraram que o uso de
Tabela 3 - Efeito da cloração da água de beber e do sexo sobre ganho de peso (g) e consumo de água, Experimento 2

Table 3 - Effect of driking water chlorination and sex on the weight gain $(\mathrm{g})$ and water intake, Experiment 2

Tratamento Idade (dias)

Treatment Age (days)

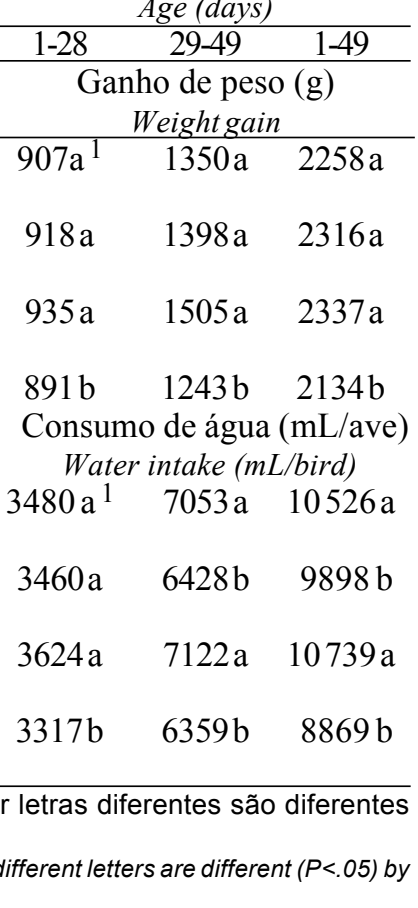

Sem cloro

Without chloride

Com cloro

With chloride

Macho

Male

Fêmea

Female

Sem cloro

Withoutchloride

Com cloro

With chloride

Macho

Male

Fêmea

Female

${ }^{1}$ Médias, na coluna, seguidas por letras diferentes são diferentes $(P<0,05)$ pelo teste $F$.

${ }^{1}$ Means, within a column, followed by different letters are different $(P<.05)$ by F test.

$6,25 \mathrm{~g}$ de bicarbonato de sódio/litro $(0,65 \%)$ na água de beber de frangos submetidos ao estresse calórico agudo resultou em aumento de $20 \%$ no consumo de água e redução na mortalidade. SMITH e TEETER (1987) observaram melhora significativa no consumo de água, na taxa de crescimento e na conversão alimentar, quando a água de beber de frangos de corte foi suplementada com $0,36 \%$ de $\mathrm{KCl}$. GLISTA e SCOTT (1949) também verificaram aumento no consumo de água, à medida que se elevou o nível de óleo de soja na ração. No entanto, os resultados deste experimento não evidenciaram efeito do nível energético da ração sobre o consumo de água.

Analisando-se os dados referentes a cloração da água de beber, sobre a ingestão da mesma (Tabela 3 - Experimento 2), observou-se menor consumo nas aves que receberam água clorada (5 ppm). DAMRON e FLUKER (1993), também, verificaram redução na ingestão de água em frangos de corte e galinhas poedeiras, quando receberam água tratada com hipoclorito de sódio e o nível de 100 e 40 ppm, respectivamente. No entanto, MURPHY et al. (1987) verificaram redução no consumo de água de frangos recebendo apenas 2 ppm de cloro. 
546 Rev. bras. zootec.

\begin{tabular}{|c|c|c|c|c|c|}
\hline \multirow{3}{*}{$\overline{\text { Item }}$} & \multirow{3}{*}{$\begin{array}{c}\text { Tratamento } \\
\text { Treatment }\end{array}$} & \multirow{2}{*}{\multicolumn{4}{|c|}{ Horário de coleta }} \\
\hline & & & & & \\
\hline & & $8: 00$ & $11: 00$ & $14: 00$ & $17: 00$ \\
\hline \multirow{2}{*}{$\begin{array}{l}\mathrm{DQO}(\mathrm{mg} / \mathrm{l}) \\
B O D(m g / l)\end{array}$} & Sem cloro $^{1}$ & 1905 & 3776 & 7096 & 10218 \\
\hline & Com cloro $^{2}$ & 1583 & 8001 & 7740 & 7007 \\
\hline \multirow{2}{*}{$\begin{array}{l}\text { Amônia }(\mathrm{mg} / \mathrm{l}) \\
\text { Ammonia }(\mathrm{mg} / \mathrm{l})\end{array}$} & Sem cloro & 270 & 352 & 127 & 392 \\
\hline & Com cloro & 308 & 550 & 392 & 448 \\
\hline \multirow{2}{*}{$\mathrm{pH}$} & Sem cloro & 7,85 & 7,91 & 7,08 & 7,43 \\
\hline & Com cloro & 7,78 & 7,90 & 7,43 & 7,28 \\
\hline \multirow{3}{*}{$\begin{array}{l}\text { Contagem bacteriana } \\
(\log \mathrm{UFC} / \mathrm{ml}) \\
\text { Bacterial number }\end{array}$} & Sem cloro & 9,51 & 10,38 & 10,94 & 12,83 \\
\hline & Com cloro & 5,88 & 8,06 & 9,55 & 10,26 \\
\hline & Sem cloro & 77 & 393 & 943 & 2746 \\
\hline $\begin{array}{l}\text { Sólidos totais } \\
\text { Total solids }\end{array}$ & Com cloro & 953 & 1006 & 972 & 1367 \\
\hline
\end{tabular}

${ }^{1}$ Sem cloro (without chloride), ${ }^{2}$ com cloro (with choride).

Tabela 5 - Média dos valores de cloro residual (ppm) na água de beber, para as diferentes idades dos frangos e tempos de coleta após cloração, Experimento 2

Table 5 - Mean of residual chloride ( $\mathrm{ppm}$ ) in drinking water for the broiler different ages and collection time after chlorination, Experiment 2

\begin{tabular}{|c|c|c|c|c|c|c|c|}
\hline \multirow{3}{*}{$\begin{array}{l}\text { Idade dos frangos (dias) } \\
\text { Broiler age (days) }\end{array}$} & \multicolumn{7}{|c|}{ Horas após a cloração } \\
\hline & & & Hours & hlorin & & & \\
\hline & 0 & 2 & 4 & 6 & 8 & 10 & 12 \\
\hline 1 & 5 & 1,50 & 0,30 & 0,10 & 0 & 0 & 0 \\
\hline 2 & 5 & 2,95 & 1,90 & 1,46 & 0,83 & 0,22 & 0 \\
\hline 3 & 5 & 2,90 & 2,75 & 1,09 & 0,28 & 0,16 & 0 \\
\hline 9 & 5 & 1,88 & 0,69 & 0,27 & 0 & 0 & 0 \\
\hline 16 & 5 & 1,76 & 0,19 & 0 & 0 & 0 & 0 \\
\hline 41 & 5 & 0,35 & 0 & 0 & 0 & 0 & 0 \\
\hline 47 & 5 & 0,42 & 0 & 0 & 0 & 0 & 0 \\
\hline
\end{tabular}

\section{Conclusões}

Os resultados obtidos nestes experimentos evidenciam que os níveis energéticos das rações testadas não influenciaram o consumo de água dos frangos de corte. Já a adição de hipoclorito de sódio $(5 \mathrm{ppm})$ reduziu a ingestão de água pelo frango, porém sem influenciar o ganho de peso das aves tratadas.

Os frangos de corte machos apresentaram médias de consumo de água superiores às fêmeas, independente do nível energético da ração ou cloração da água.

A adição de hipoclorito de sódio (5 ppm) na água melhorou a qualidade desta, sendo observado menor número de unidades formadoras de colônias de bactérias e pH mais estável. 


\section{Referências Bibliográficas}

AMARAL, L.A. do, NADER FILHO, A., ROSSI JR., O.D. et al. 1994. Características físicas, químicas e higiênico-sanitária da água de três mananciais de abastecimento público. $R$. Latino Amer. Microb., 36(1):1-69.

AMARAL, L.A. do, NADER FILHO, A., ROSSI JR., O.D. et al. 1995. Características microbiológicas da água utilizada na obtenção de leite. Pesq. Vet. Bras., 15(2/3):85-88.

BARTOLOMEW, G.A., CADE, T.J. 1963. The water economy of land birds. Auk, 80(3):504-539.

BRANTON, S.L., REECE, F.N., DEATON, J.W. 1986. Use of ammonium chloride and sodium bicarbonate in acute heat exposure of broilers. Poult. Sci., 65(9):1659-1663.

DAMRON, B.L., FLUNKER, L.K. 1993. Broiler chick and laying hen tolerance to sodium hypochlorite in drinking water. Poult. Sci., 72(9):1650-1655.

ESTAT- Sistema de Análises Estatísticas. 1996. FACULDADE DE CIÊNCIAS AGRÁRIAS E VETERINÁRIAS, DEPARTAMENTO DE CIENCIAS EXATAS. Jaboticabal: UNESP.

GRIZZLE, J.M., AMBRUST, T.A., BRYAN, M.A. et al. 1997a. Water quality. I: The effect of water nitrate and bacteria on broiler growth performance. J. Applied Poult. Res., 6(1):48-55.

GRIZZLE, J.M., AMBRUST, T.A., BRYAN, M.A. et al. 1997b. Water quality II: The effect of water nitrate and bacteria on broiler breeder performance. J. Applied Poult. Res., 6(1):56-63.

GLISTA, W.A., SCOTT, H.M. 1949. Growth and feed efficiency studies with broilers. 2 . Gross water consumption in reletion to the level of soybean oil meal in the ration. Poult. Sci., 28(5):747-749.

HOWIE, M. Broilers can adjust feed intake based on dietary energy levels. Feedstuffs, 68(33):10, 1996.

LEESON, S., SUMMERS, J.D., CASTON, L.J. 1992. Response of broilers to feed restriction or diet dilution in the finisher period. Poult. Sci., 71(12):2056-2064.

MACARI, M., FURLAN, R.L., GONZALES, E. 1994. Fisiologia Aviária Aplicada a Frangos de Corte. 1 ed. Jaboticabal: FUNEP. 296p.

MACARI, M. 1995. Cuide da água, a criação agradece. Avicultura Industrial, (1022):13-20.
MACARI, M. 1996. Água na avicultura industrial, 1. ed. Jaboticabal:FUNEP, $128 \mathrm{p}$.

MOORE, B.W., McClUNG, M.R., PETERSON, R.A. et al. 1971. The effects of water treatment on broiler performance. Poult. Sci., 50(5):1608-1609.

MURPHY, D.W., WABECK, C.J., CARR, L.E. 1987. Chlorination effects on broiler performance and environments. Poult. Sci., 66:149. (Abstract) (suppl.1).

PATRICK, H. 1955. The influence of protein source on consumption and excretion of water and excreta voided by broiler chicks. Poult. Sci., 34(1):155-157.

PATRICK, H., FERRISE, A. 1962. The water requirement of broilers. Poult. Sci., 41(5):1363-1367.

ROSTAGNO, H.S., SILVA, D.S., COSTA, P.M.A. et al. 1985. Composição de alimentos e exigências nutricionais de aves e suínos. Viçosa, UFV. 59p (Tabelas Brasileiras).

SIMON, V.A., OLIVEIRA, C. 1996. Vacinação em avicultura através da água de bebida. In: MACARI, M. Água na avicultura industrial, 1. ed. Jaboticabal: FUNEP. p.73-85.

SMITH, M.O., TEETER, R.G. 1987. Potassium balance of the 5 to 8 week old broiler exposed to constant heat or cycling high temperature stress and effects of supplemental potassium chloride on body weight gain and feed efficiency. Poult. Sci., 66(3):487-492.

TEETER, R.G. 1994. Optimizing production of heat stressed broilers. Poult. Digest., 53(5):10-27.

VOHRA, P.N. 1980. Water quality for poultry use. Feedstuffs, 52(27):24-25.

Recebido em: 11/09/97

Aceito em: 27/11/98 